\title{
Increased Performance of an all-Organic Redox Flow Battery model by Nitration of the [4]Helicenium Ion Electrolyte
}

\author{
Jules Moutet, David Mills, Md Mubarak Hossain and Thomas L. Gianetti*
}

Redox Flow Batteries (RFBs) through their scalable design and virtually unlimited capacity, are promising candidates for large-scale energy storage. While recent advances in the development of redox-active bipolar organic molecules satisfy the prerequisites for the pioneering Symmetrical all-Organic Redox Flow Batteries (SORFBs) emerging, problems of low durability or low energy density remain a bottleneck for their wide-spread application. The present work reports that nitration of the [4]helicenium ion core $\left(\mathrm{DMQA}^{+}\right)$result in a significant enhancement of the electrochemical performance of DMQA as electrolyte for SORFBs. The physical and kinetic properties of ${ }^{{ }^{N O 2} \mathbf{C}^{+}}$were evaluated by cyclic voltammetry (CV) and UV-visible spectroscopy in acetonitrile and compared to those of its precursor ${ }^{\mathbf{H}} \mathbf{C}^{+}$. The electrons storage ability of ${ }^{\mathrm{NO} 2} \mathrm{C}^{+}$was investigated in three differents type of static $\mathrm{H}$-cell experiments. In the first experiment, ${ }^{\mathrm{NO} 2} \mathrm{C}^{+}$provided an open circuit voltage (OCV) of $2.24 \mathrm{~V}$ and demonstrated good stability, as well as high coulombic ( $>98 \%)$ efficiencies, over more than 200 charge/discharge cycles. In the second experiment, a charge-discharge cycling over the entire redox window of ${ }^{{ }^{O} 2} \mathrm{C}^{+}(\mathrm{OCV}>3 \mathrm{~V})$ resulted in 80 cycles at a potential energy density above $12 \mathrm{Wh} / \mathrm{L}$. During the last epxeriment, a bipolarization stress-test was performed during which ${ }^{{ }^{02}} \mathbf{C}^{+}$demonstrated a remarkable durability of 90 cycles at $100 \%$ load with a perfect retention of capacity and coulombic efficiency. The electrochemical performance results of this enhanced redox material highlights that $\mathrm{DMQA}^{+}$ions are robust and versatile materials for the emergence of symmetrical all-Organic ORFB

\section{Introduction}

Despite the increase need for renewable energies, such as wind and solar energy, the intermittency of these energy sources prevent them to meet the essential requirement of a constant supply. ${ }^{1}$ Incorporation of efficient storage systems, such as batteries, is a growing need for optimal integration of renewable energies into the grid. ${ }^{2-4}$ Currently the most widespread systems of Electric Energy Storage (EES) are mainly based on the high-performance lithium-ion batteries. $^{5,6}$ But we note that the availability of this metal is quickly being overtaken by the current demand. ${ }^{7,8}$ One promising technology is Redox Flow Batteries (RFBs), ${ }^{9-13}$ which store energy in liquid electrolytes that contain dissolved redox-active species that are pumped from storage tanks to an electrochemical cell. The conversion between electrical and chemical energy occurs at the cell, resulting in a decoupled power and capacity. As a consequence, their capacity is virtually unlimited since it relies essentially on the volume of storage tanks, which makes RFBs a sustainable response to largescale electricity storage. ${ }^{14}$ Currently, aqueous allvanadium RFBs (VRFBs), which uses water-soluble vanadium ions in different oxidation states as redoxactive species, is considered a robust choice and is an established EES technology. ${ }^{10,15-17}$ VRFBs are also an outstanding example of a symmetrical RFB using only one element in both electrolytes, allowing the crossing of electrolytes to result only in self-discharge of the battery and not in persistent cross-contamination. ${ }^{18}$ Although other metal-based electrolytes have been explored, ${ }^{19-22}$ the utility of metal-based RFB is limited due to their high cost and toxicity. ${ }^{23,24}$ Driven by the continuous demand towards low-cost and large-scale organic RFB (ORFB), redox-active organic materials (ROMs) have emerged as an attractive and powerful manifold thanks to their sustainable, synthetically tunable, and potentially inexpensive raw materials. ${ }^{25-}$ 32

In order to be competitive with existing solutions, special attention must be paid to the ORFB energy density $\left(\mathrm{E}_{\mathrm{d}}\right)$. This is defined as $\mathrm{E}_{\mathrm{d}}=\mathrm{nFV} \mathrm{V}_{\text {cell }} \mathrm{C}_{\text {active }} 0.5\left(\mathrm{E}_{\mathrm{d}}\right.$ in Wh. $\left.\mathrm{L}^{-1}\right)^{26}$ where $n$ is the number of electrons in the redox process, $F$ is the Faraday constant in A.h $/ \mathrm{L}, V_{\text {cell }}$ is the open circuit voltage, and $C_{\text {active }}$ is the concentration of redox-active species (equal to the equivalent electron concentration at the cathode and the anode). Evidently, with the aim of increase the energy density of ORFBs, three parameters have to be addressed:

- the solubility of the ROM, which is already commonly adjustable in aqueous media, ${ }^{29,33,34}$ but is still rarely optimized for non-aqueous solvents. ${ }^{35,36}$

- the open circuit voltage (OCV), which in the case of a symmetrical RFB corresponds to a potential gap increase between the redox species.

- the number of electrons involved and/or the number of electronic processes. 
While impressive advances have been made in recent years in the field of aqueous RFBs, ${ }^{37-39}$ the overall ROM performance is inherently limited by the narrow redox-innocent window of water $(<1.23 \mathrm{~V})$. Therefore, research for high energy density ORFB systems has already started to move towards non-aqueous electrolytes based on organic solvents, with wider electrochemical stability window (NAORFBs).

We have recently demonstrated that 1,3dipropylodimethoxyquinolinoacridinium

tetrafluoroborate salt helicene (denoted ${ }^{\mathrm{H}} \mathrm{C}^{+}$, see Scheme 1$)^{41}$ possess remarkable performance as electrolyte material in symmetrical ORFBs via its three stable ${ }^{\mathrm{H}} \mathbf{C}^{\bullet++} /{ }^{\mathrm{H}} \mathbf{C}^{+} /{ }^{\mathrm{H}} \mathbf{C}^{\bullet}$ redox couple. The ${ }^{\mathrm{H}} \mathbf{C}^{+}$ions showed impressive redox stability, and a highly open circuit potential of $2.12 \mathrm{~V}$ in a static model of RFB. ${ }^{40}$ Here we investigate the study and use of a derivative of this DMQA ${ }^{+}$substituted by an electron withdrawing group as an electrolyte for high-voltage RFBs. Access to a nitro derivative could be easily obtained by late functionalization nitration under acidic conditions in dichloromethane (Scheme 1) ${ }^{41}$ This nitro-helicenium ion $\left[{ }^{n} \mathrm{Pr}-\mathrm{DMQA}^{\mathrm{NO} 2}\right]\left[\mathrm{BF}_{4}\right]$, denoted ${ }^{\mathrm{NO} 2} \mathrm{C}^{+}$throughout this report, is expected to be more soluble, to have higher potential electronic processes, and to present an additional reversible electronic process in reduction. Herein, we report the in-depth study of the electronic behaviors ${ }^{\mathrm{NO} 2} \mathrm{C}^{+}$as an improved as $\mathrm{ROM}$ for NAORFBs.

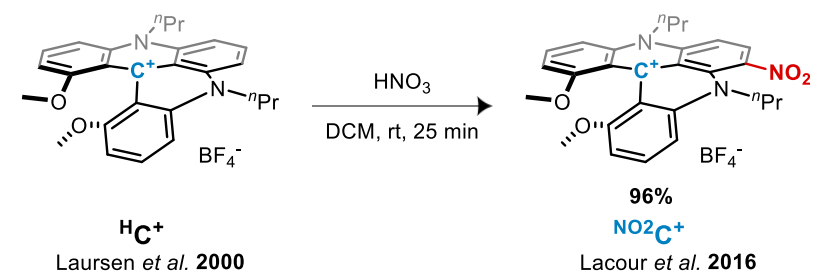

Scheme 1. Nitration of N,N'-dialkyl-1,13dimethoxyquinacrinidium $\left(\mathrm{DMQA}^{+}\right){ }^{\mathrm{H}} \mathrm{C}^{+}$to form ${ }^{\mathrm{NO} 2} \mathrm{C}^{+}$.

\section{Experimental}

\section{Chemicals, reagents, and synthesis of ${ }^{\mathrm{NO} 2} \mathrm{C}^{+}$}

All solvents were purified by SPS or distilled over the drying agents indicated. Dried solvents and liquid reagents were transferred by oven-dried syringes or hypodermic syringes. The supporting electrolyte tetrabutylammonium hexafluorophosphate $\left(\mathrm{TBAPF}_{6}\right)$ was recrystallized three times from ethanol, then dried at $80{ }^{\circ} \mathrm{C}$ for three days prior to use. The racemic 1,13 dimethoxy-6-nitro-5,9-dipropyl-9,13b-dihydro-5Hquinolino[2,3,4-kl]acridinium tetrafluoroborate salt $\left({ }^{\mathrm{NO} 2} \mathrm{C}^{+}\right)$was prepared according to Lacour et al. report and was purified by crystallization by slow vapor diffusion of $\mathrm{Et}_{2} \mathrm{O}$ in concentrated $\mathrm{DCM}$ or $\mathrm{CH}_{3} \mathrm{CN}$ solution. ${ }^{41}$

\section{UV-Vis measurements}

Absorption spectra were recorded on a ThermoScientific Evolution 220 UV-Visible spectrophotometer at $25{ }^{\circ} \mathrm{C}$ in dried $\mathrm{CH}_{3} \mathrm{CN}$ at different concentrations. All UV samples for calibration curves were prepared under an inert atmosphere in a Vigor glovebox maintained at less than $1 \mathrm{ppm} \mathrm{H}_{2} \mathrm{O} / \mathrm{O}_{2}$. A $3 \mathrm{~mL}$ gas-tight cuvette (Quartz Cuvette Self Masking Screw Cap) was used for anaerobic acquisition of all spectra.

\section{Electrochemical studies}

Electrochemical analyses were conducted inside a $\mathrm{N}_{2}$ filled Vigor glovebox using a BioLogic SP-200 potentiostat/galvanostat and the EC-Lab ${ }^{\circledR}$ software (v11.33) provided by BioLogic Science Instruments. For convenience, all potentials are given $v s$. the reference electrode $\mathrm{AgNO}_{3} / \mathrm{Ag}$.

Cyclic voltammograms (CV) were measured in a three-electrode electrochemical cell, consisting of a platinum wire counter electrode, a $\mathrm{AgNO}_{3} / \mathrm{Ag}$ reference electrode $\left(0.01 \mathrm{M} \mathrm{AgNO}_{3}\right.$ in $0.1 \mathrm{M} \mathrm{TBAPF}_{6}$ in $\left.\mathrm{CH}_{3} \mathrm{CN}\right)$, and a platinum working electrode $(0.031$ $\mathrm{cm}^{2}$, CH Instrument, Inc.). The working electrode was polished prior to each record using aluminium oxide polishing paper and anhydrous $\mathrm{CH}_{3} \mathrm{CN}$ to remove residual particles. CVs were recorded at different scan rates $(10,25,75,100,250,400$, and $500 \mathrm{mV} / \mathrm{s})$ in an $\mathrm{CH}_{3} \mathrm{CN}$ electrolyte containing $1 \mathrm{mM}^{{ }^{\mathrm{NO}} 2} \mathrm{C}^{+}$and $0.1 \mathrm{M}$ $\mathrm{TBAPF}_{6}$.

\section{Static cell experiments}

Galvanostatic cycling experiments in static conditions were carried out in a custom-made glass H-cell (see Figure S11). A $2 \mathrm{~mm}$ fine porous glass frit $(4-5.5 \mu \mathrm{m}$ holes diameter) was used as the separator ${ }^{42,43}$ and a reference electrode $\left(0.01 \mathrm{M} \mathrm{AgNO}_{3} / \mathrm{Ag} 0.01 \mathrm{M}\right.$ in 0.1 M TBAPF 6 in $\left.\mathrm{CH}_{3} \mathrm{CN}\right) .10 \mathrm{~mL}$ of ${ }^{\mathrm{NO}} \mathbf{C}^{+}$solution $(0.1$ $\mathrm{M} \mathrm{TBAPF}_{6}$ ) was used to study the cycling in the cell. Reticulated vitreous carbon (RVC) electrodes (100 ppi Duocel $(\mathbb{R})$ were cut into rods of the dimensions $0.5 \mathrm{~cm}$ $\mathrm{x} 0.5 \mathrm{~cm} \times 4 \mathrm{~cm}$ and positioned about $2 \mathrm{~cm}$ deep in solution (active surface $\sim 33 \mathrm{~cm}^{2}$ per electrode). To rule out contamination processes, the electrodes were singly-used. A Constant Current following by a Constant Voltage galvanostatic charging (CCCV GCPL protocol) at $|5| \mathrm{mA}$ current was applied via $\mathrm{RVC}$ electrodes. During charge-discharge experiments both cell's compartments were continuously stirred at 1000 rpm. 


\section{Results and discussion}

\section{Electrochemical studies}

During this work, acetonitrile was chosen as the model solvent, since it provides an exceptionally wide electrochemical stability window $(\sim 6.0 \mathrm{~V})$, has a positive impact on energy density ${ }^{44,45}$ and also proved to be suitable with $\mathrm{DMQA}^{+} .40$

In acetonitrile $\left(0.1 \mathrm{M} \mathrm{TBAPF}_{6}\right), 3$ single electron events were observed for ${ }^{{ }^{N O} 2} \mathrm{C}^{+}$(Figure 1a) in cyclic voltammetry (1b solid black line); contrasting with the 2 redox events of its ${ }^{\mathrm{H}} \mathbf{C}^{+}$parent (Figure 1b, dotted grey line). Differential Pulse Voltammetry (DPV) experiment (Figure 1b transparent colour plot) informs us about the potential at which these different events take place. The first event was identified as oneelectron reduction at $\mathrm{E}_{1 / 2}{ }^{\operatorname{Red} 1}=-0.89 \mathrm{~V}$, corresponding to the ${ }^{\mathrm{NO} 2} \mathbf{C}^{\bullet} /{ }^{\mathrm{NO} 2} \mathbf{C}^{+}$redox couple and appeared $250 \mathrm{mV}$ higher than the same process for ${ }^{\mathrm{H}} \mathbf{C}^{+}$. The one-electron process at $\mathrm{E}_{1 / 2} \operatorname{Red} 2=-1.67 \mathrm{~V}$ is attributed to the ${ }^{\mathrm{NO}} \mathrm{C}^{\bullet} / \mathrm{NO}^{\mathrm{NO}} \mathrm{C}^{\bullet-}$ transformation. ${ }^{41,46}$ Upon scanning toward the cathodic region, a one-electron oxidation wave is observed at $\mathrm{E}_{1 / 2} \mathrm{Ox}=1.35 \mathrm{~V}$, which is assigned to the ${ }^{\mathrm{NO2}} \mathbf{C}^{\bullet++} / \mathrm{NO}^{\mathbf{O}} \mathbf{C}^{+}$redox couple, and was $310 \mathrm{mV}$ higher than the ${ }^{\mathrm{H}} \mathbf{C}^{+}\left(\mathrm{E}_{1 / 2}{ }^{\mathrm{Ox}}=0.98 \mathrm{~V}\right.$ for $\left.{ }^{\mathrm{H}} \mathbf{C}^{+}\right)$.

The reversibility of these electronic processes has been investigated through the acquisition of $\mathrm{CV}$ at different scan rates in a three-electrodes cell (see Figures S3). The exhibited linear relation between measured intensity (I) in function of the square root of the scan rate (Figure 1c), indicate that the electrolyte is freely diffusing, and a complete reversibility of the three electronics processes is maintained at each speed rate. The essential electrochemical kinetic parameters were extracted from these plots (Figure 1d). The RandlesSevcik equation application (Equation S1), gave access to experimental diffusion coefficient (D) value of $9.9 \times 10^{-6} \mathrm{~cm}^{2} \cdot \mathrm{s}^{-1}$ for ${ }^{\mathrm{NO} 2} \mathrm{C}^{\bullet++} / \mathrm{NO}^{2} \mathrm{C}^{+}$pair. It is an identical value to the one exhibited by ${ }^{\mathrm{H}} \mathbf{C}^{+}$(Figure 1d in grey $\left.\mathrm{D}\left(\mathrm{E}^{1}{ }_{1 / 2 \mathrm{Ox}}\right)=9.9 \times 10^{-6} \mathrm{~cm}^{2} \cdot \mathrm{s}^{-1}\right)$ and slightly higher than recent catholyte for ORFBs application. ${ }^{34,36,42,47,48}$ On the other hand the values for the reductive processes for ${ }^{{ }^{02} 2} \mathrm{C}^{+} /{ }^{\mathrm{NO} 2} \mathrm{C}^{\bullet}\left(\mathrm{D}=5.6 \times 10^{-}\right.$ $\left.{ }^{6} \mathrm{~cm}^{2} \cdot \mathrm{s}^{-1}\right)$ and ${ }^{\mathrm{NO} 2} \mathrm{C}^{\bullet} /{ }^{\mathrm{NO} 2} \mathrm{C}^{\bullet \bullet-}\left(\mathrm{D}=4.3 \times 10^{-6} \mathrm{~cm}^{2} \cdot \mathrm{s}^{-1}\right)$ couples are approximately twice as low overall as the ${ }^{\mathrm{H}} \mathrm{C}^{+}$reduction process $\left(\mathrm{D}\left(\mathrm{E}^{1}{ }_{1 / 2 \mathrm{Red}}\right)=9.4 \times 10^{-6} \mathrm{~cm}^{2} \cdot \mathrm{s}^{-1}\right)$ and is similar to recent anolytes studied. ${ }^{36,47,49-52}$

The useful work reported by Lavagnini et al. was used to determine the electron transfer rate constant $\left(\mathrm{k}^{0}\right)$ using these D-values (Figure 1d, equation S2-3). ${ }^{53,54}$ The values of $\mathrm{k}^{0}=3.7 \times 10^{-2} \mathrm{~cm} \cdot \mathrm{s}^{-1}$ for ${ }^{{ }^{N O 2}} \mathbf{C}^{+} / \mathrm{NO}^{2} \mathbf{C}^{\bullet}$ and $\mathrm{k}^{0}=1.2 \times 10^{-2} \mathrm{~cm} \cdot \mathrm{s}^{-1}$ for ${ }^{{ }^{\mathrm{NO}} 2} \mathbf{C}^{\bullet} /{ }^{\mathrm{NO} 2} \mathbf{C}^{\bullet \bullet-}$ redox couples are quite similar, and their average provides a value close to the one of the couple ${ }^{\mathrm{H}} \mathbf{C}^{+} /{ }^{\mathrm{H}} \mathbf{C}^{\bullet}\left(\mathrm{k}^{0}=2.6\right.$ $\left.\times 10^{-2} \mathrm{~cm} \cdot \mathrm{s}^{-1}\right)$. However the $\mathrm{k}^{0}=7.9 \times 10^{-3} \mathrm{~cm} \cdot \mathrm{s}^{-1}$ value of ${ }^{{ }^{-2} 2} \mathbf{C}^{\bullet++} / \mathrm{NO}^{-2} \mathbf{C}^{+}$is lower than the one observed for ${ }^{\mathrm{H}} \mathbf{C}^{+}\left(\mathrm{k}^{0}=2.0 \times 10^{-2} \mathrm{~cm} . \mathrm{s}^{-1}\right)$ and lower than the one identified for the ${ }^{\mathrm{NO2}} \mathrm{C}^{+}$reduction phenomena which are both comparable to redox shuttles used in NAORFBs. ${ }^{42,45,51}$

We attribute the slight differences in parameters observed between each process to the dissymmetrization of the [4]helicenium core by the $\mathrm{NO}_{2}$ moiety addition. We will pay attention to their impacts in static RFB experiments. The electrokinetic parameters obtained suggest that this electrolyte is suitable for ORFB application. We could expect in a symmetrical use, an OCV of $2.24 \mathrm{~V}$. The presence of a second process in reduction, accessible by a second

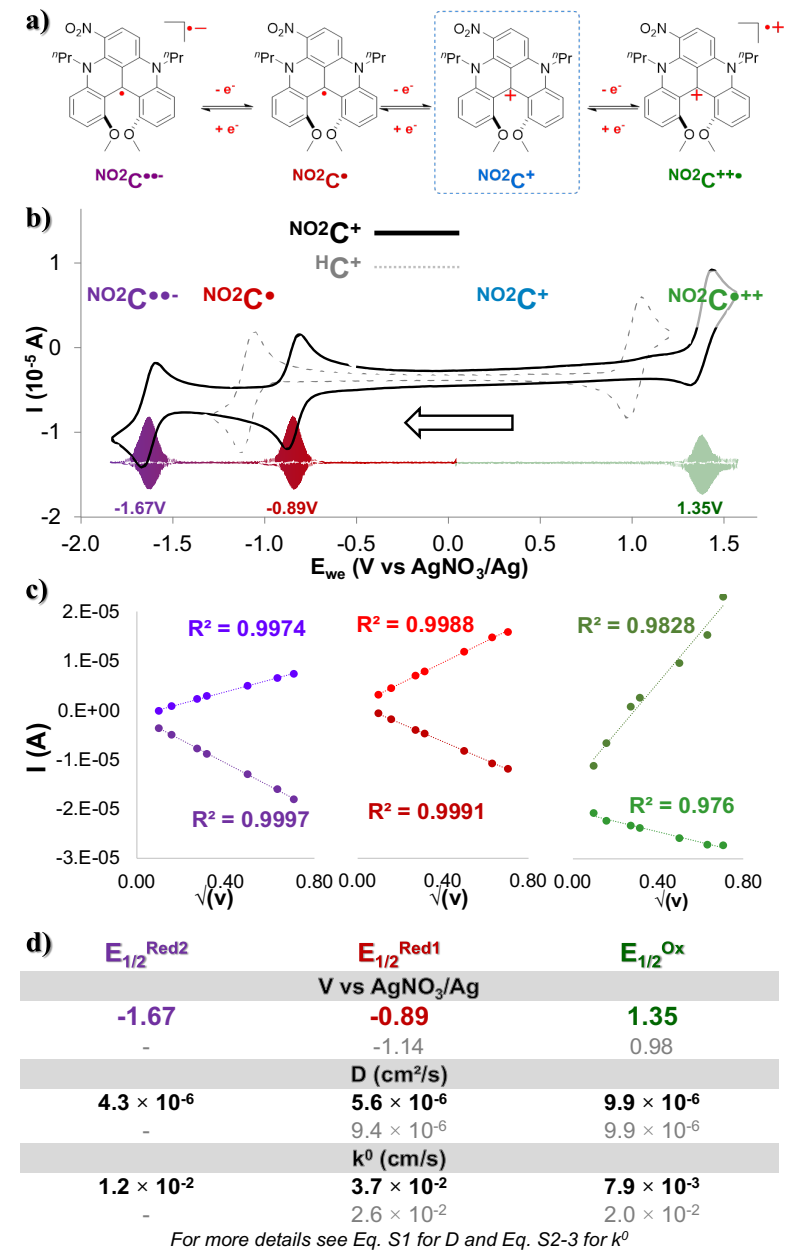

Figure 1: (a) Four different oxidation states of ${ }^{\mathrm{NO}^{2}} \mathrm{C}^{+}$.(b) $\mathrm{CV}$ at scan rate of $100 \mathrm{mV} \mathrm{s}^{-1}$ for ${ }^{{ }^{\mathrm{O} O 2}} \mathrm{C}^{+}$in black, ${ }^{\mathrm{H}} \mathrm{C}^{+}$in grey and (c) measured intensity (I) reported as a function of the square root of the scan rate $\left(10-500 \mathrm{mV} \mathrm{s}^{-1}\right)$ for the 3 electronic processes of $1.0 \mathrm{mM}{ }^{{ }^{\mathrm{NO}} 2} \mathrm{C}^{+}$solution in $0.1 \mathrm{M}$ $\mathrm{TBAPF}_{6} / \mathrm{CH}_{3} \mathrm{CN}$. (d) $\mathrm{D}$ and $\mathrm{k}^{0}$ determined by studying $\mathrm{CVs}$ at different scan rates from 10 to $500 \mathrm{mV} . \mathrm{s}^{-1}$ for ${ }^{{ }^{N O 2}} \mathrm{C}^{+}$in black, ${ }^{\mathbf{H}} \mathbf{C}^{+}$in grey. 
mono-electronic transfer implies the possible access to two electrons storage with the ${ }^{\mathrm{NO}} \mathbf{C}^{\boldsymbol{0}^{0} \text { - }}$ formation, with a high OCV of $3.02 \mathrm{~V}$.

\section{Saturation concentration of the different oxidation states}

The saturation concentrations of ${ }^{{ }^{\mathrm{O}} 2} \mathrm{C}^{+}$and ${ }^{\mathrm{NO}_{2}} \mathrm{C}^{\bullet}$ in acetonitrile were evaluated using $\mathrm{UV}-$ visible spectroscopy (see Figures S5-8). Despite numerous attempts to synthetize and isolate ${ }^{\mathrm{NO} 2} \mathrm{C}^{{ }^{+++}}$in its pure form, our efforts have been unfruitful. The ${ }^{\text {NO2 }} \mathbf{C}^{\bullet \bullet-}$ formation via an alkaline double-reduction $\left(\mathrm{KC}_{8}\right)$ has been also investigated, and if crystals could be obtained at low temperature $\left(-35^{\circ} \mathrm{C}\right)$, those seemed highly temperature sensitive and insufficiently stable to be used for a UV-Vis calibration curve or further analysis, even with pre-cooled $\mathrm{CH}_{3} \mathrm{CN}$ solubilization. This observation is correlated by the DFT calculations performed, indicating a predominance of the more reactive triplet state for ${ }^{\text {NO2 }} \mathbf{C}^{\bullet \bullet-}$ (See Figure S11). In pure $\mathrm{CH}_{3} \mathrm{CN},{ }^{\mathrm{NO}}{ }^{\mathbf{2}} \mathrm{C}^{+}$sat exhibits a saturation concentration of $154 \mathrm{mM}$, whereas ${ }^{{ }^{\mathbf{N O} 2}} \mathbf{C}^{\bullet}$ sat is slightly lower with a value of $110 \mathrm{mM}$. In both states, the solubility exhibited is above $>0.1 \mathrm{M}$. The introduction of a nitro group modified the electrochemical behavior of the DMQA scaffold, and also significantly increases its solubility $\left({ }^{\mathrm{H}} \mathbf{C}^{+}{ }_{\text {sat }}=32 \mathrm{mM}\right.$ vs. ${ }^{\mathrm{NO} 2} \mathbf{C}^{+}{ }_{\text {sat }}=154 \mathrm{mM}$ in acetonitrile). This increased solubility will lead to a higher energy density of $\mathrm{E}_{\mathrm{d}}\left({ }^{\mathrm{NO} 2} \mathrm{C}^{+}\right)=9.25 \mathrm{Wh} / \mathrm{L}$ compared to the $\mathrm{E}_{\mathrm{d}}\left({ }^{\mathrm{H}} \mathrm{C}^{+}\right)=1.84 \mathrm{Wh} / \mathrm{L}$. In a single latefunctionalization step, the energy density of the previous ROM was increased by a factor of 5 .

\section{Galvanostatic Cycling with Potential Limitation cycling}

The electrochemical stability of the electrolyte ${ }^{{ }^{N O 2}} \mathrm{C}^{+}$ was evaluated by bulk electrolysis charge/discharge cycling using a three-electrode $\mathrm{H}$-cell as model for a redox flow cell setup. Although it does not allow to work at high concentrations, Hansmann et al. have shown that such electrochemical cell designs are acceptable test beds for organic ROMs in RFBs performance. ${ }^{43,51}$

\section{MONO-POLARIZATION CYCLING, OCV $=2.24 \mathrm{~V}$}

We first investigated the use of this ${ }^{{ }^{N O} 2} \mathrm{C}^{+}$as electrolyte for ORFB application in symmetrical step. Both sides of the cell were equally filled with a $1.0 \mathrm{mM}$ solution of ${ }^{\mathrm{NO} 2} \mathbf{C}^{+}\left(0.1 \mathrm{M} \mathrm{TBAPF} / \mathrm{CH}_{3} \mathrm{CN}\right)$ (Figure 2a). One cycle corresponds to a charge followed by a discharge. During the charge, in the "catholyte" compartment ( $E_{\mathrm{w}}$ side of the cell) ${ }^{\mathrm{NO} 2} \mathrm{C}^{+}$is oxidized to ${ }^{\text {NO2 }} \mathbf{C}^{\bullet++}$, while in the "anolyte" compartment $\left(E_{c}\right.$ of the cell) ${ }^{\mathrm{NO}_{2}} \mathrm{C}^{+}$is reduced to ${ }^{{ }^{\mathrm{O} O} 2} \mathrm{C}^{\bullet}$.

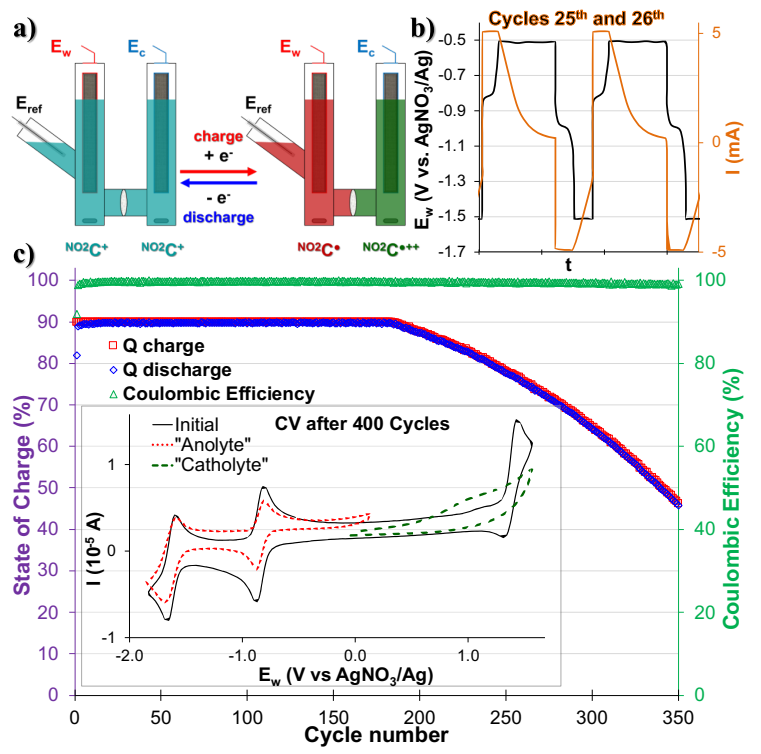

Figure 2. (a) Scheme showing the mono-electronic charge-discharge cycles in a symmetric H-cell. The color code is indicative of the electrolyte oxidation degree. (b) Zoom-in of $\mathrm{E}_{\mathrm{we}}$ along the $25^{\text {th }}$ to $26^{\text {th }}$ cycles of cycling and species formation in $\mathrm{E}_{\text {ref }}$ compartment. (c) $\mathrm{Q}$ of charge-discharge processes and Coulombic efficiency monitoring over 350 cycles of monoelectronic exchange. Inset shows CV analysis at $100 \mathrm{mV} \cdot \mathrm{s}^{-1}$ of respective contents of each side of the cell after 400 cycles.

In the first instance, mono-electronic transfer at $90 \%$ of theoretical capacity ( $90 \%$ state of charge, "SOC") cycles (Figure 2 and Figure S13-14) were performed. A constant current followed by a constant voltage galvanostatic charging (CCCV GCPL protocol) of $|5|$ $\mathrm{mA}$ was applied with potential boundaries at $-1.49 \mathrm{~V}$ and $-0.49 \mathrm{~V}$ vs $\mathrm{E}_{\mathrm{ref}}$. During the charge-discharge cycles two plateaux at ca. $-0.92 \mathrm{~V}$ and $-0.86 \mathrm{~V}$ in the $\mathrm{E}_{\mathrm{w}}$ voltage curves were observed and assigned to the electronic processes of ${ }^{\mathrm{NO}_{2}} \mathrm{C}^{+} /{ }^{\mathrm{NO}} \mathrm{C}^{\bullet}$ redox couple (Figure 2b and S15). Satisfactorily, the cell monitoring Figure 2c shows that the Coulombic efficiency (CE, green triangle) remains constant and close to $100 \%$ throughout the experiment. Furthermore, the capacity Q (red and blue squares) exhibited a plateau, with an initial capacity $(90 \%$ SOC or $Q_{\text {theoretical }}$ ) retention over $\sim 200$ cycles. The decrease in the capacity started at the $186^{\text {th }}$ cycle, and the system then lost $0.32 \%$ capacity retention per cycle, reaching a value of $\mathrm{Q}=50 \% \mathrm{Q}_{\text {theoritical }}$ at the $340^{\text {th }}$ cycle. The cycling was stopped at the $400^{\text {th }}$ cycle and the final capacity reached was $\mathrm{Q}_{\text {final }}=33 \%$ Q $\mathrm{Q}_{\text {theoretical. }}$. Differences in solution mobility and speed of electronic exchange led to faster system fatigue and electrolyte deterioration. The $\mathrm{CV}$ analysis of each compartment after 400 monopolarization cycles of the $\mathrm{H}$-cell revealed that the catholytic compartment is 
strongly degraded with broadened and poorly defined profile, highlighting a deterioration of the oxidation process of ${ }^{\mathrm{NO} 2} \mathrm{C}^{+}$into ${ }^{\mathrm{NO}} \mathrm{C}^{\bullet++}$ (Figure $2 \mathrm{c}$ ). In the anolytic compartment, we noted a beginning of fatigue after 400 cycles (see Figure $\mathrm{S} 15$ ) with the $\mathrm{E}_{1 / 2} \operatorname{Red} 1$ process of ${ }^{{ }^{\mathrm{NO}} 2} \mathrm{C}^{+}$to ${ }^{{ }^{\mathrm{OO}}} \mathrm{C}^{\bullet}$ decreased slightly in intensity and resolution. Thus, despite the introduction of an $\mathrm{NO}_{2}$ moities seems to have a negative effect on the robustness of our electrolyte, this comes along with a dramatic increase in the solubility of this ROM. In a symmetrical cell with mono-polarization it allowed to increase the gap between the two redox events in oxidation and reduction, resulting in a theoretical $\mathrm{Ed}$ of $9.25 \mathrm{Wh} / \mathrm{L}$, much higher than the $1.84 \mathrm{Wh} / \mathrm{L}$ of its parent ion ${ }^{\mathrm{H}} \mathbf{C}^{+},{ }^{40}$ that can be deliver for almost 200 cycles. It has also been noted that, the monopolarization cycles seemed not affect the second electronic transfer $\mathrm{E}_{1 / 2}{ }^{\mathrm{Red} 2}$ at $-1.67 \mathrm{~V}$ which led us to expect a resilient behaviour during 2-electron reduction storage experiments.

\section{DOUBLE REDUCTION CYCLING, OCV $=3.02 \mathrm{~V}$}

The use of multi-electrons storage in order to increase the energy density of a system is currently being studied for ARFBs, ${ }^{35,55-57}$ but remains under explored for NARFBs. ${ }^{34,36}$

We studied the viability of a two-electron storage ORFB with ${ }^{\text {NO2 }} \mathbf{C}^{+}$using the H-Cell. In this configuration, the cell is loaded asymmetrically with the same ROM on both sides: on the catholyte side the ${ }^{\mathrm{NO}} \mathrm{C}^{+}$concentration is twice as high as on the anolyte side (ratio 2:1, for the same $0.1 \mathrm{M} \mathrm{TBAPF}$ supporting salt). (Figure 3a). Since ${ }^{\mathrm{NO}} \mathrm{C}^{+}$is able to store 2 electrons, via two one-electron processes in the anodic

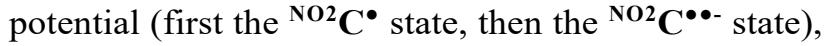
the catholyte compartment must supply 2 electrons and therefore contain a helicenium solution twice as concentrated. In this way, the following battery will be able to store twice as much current, accessing a high voltage of $3.02 \mathrm{~V}$, without cross-contamination risk and increasing the amount of ROM needed by only half. If we consider $\mathrm{C}_{\max }{ }^{\mathrm{NO} 2} \mathrm{C}^{+}=154 \mathrm{mM}$ with $\mathrm{OCV}$ of $3.02 \mathrm{~V}$, a maximum value of $\mathrm{Ed}=12.47 \mathrm{Wh} / \mathrm{L}$ could be calculated for this double reduction cycling test, i.e. 6.8 times more energy stored than in the unsubstituted helicenium ${ }^{\mathbf{H}} \mathbf{C}^{+} .40$

Before any test, the anolyte side was checked in $\mathrm{CV}$ to test the reversibility of the two process $\mathrm{E}_{1 / 2}{ }^{\text {Redl }}$ and $E_{1 / 2}{ }^{R e d 2}$ in the initial state. The concentration of the anolyte compartment -half of that of the catholyte compartment- is distinguishable by an intensity two times lower two times lower than the mother solution used to fill the catholyte side (Figure 3b inset purple trace).
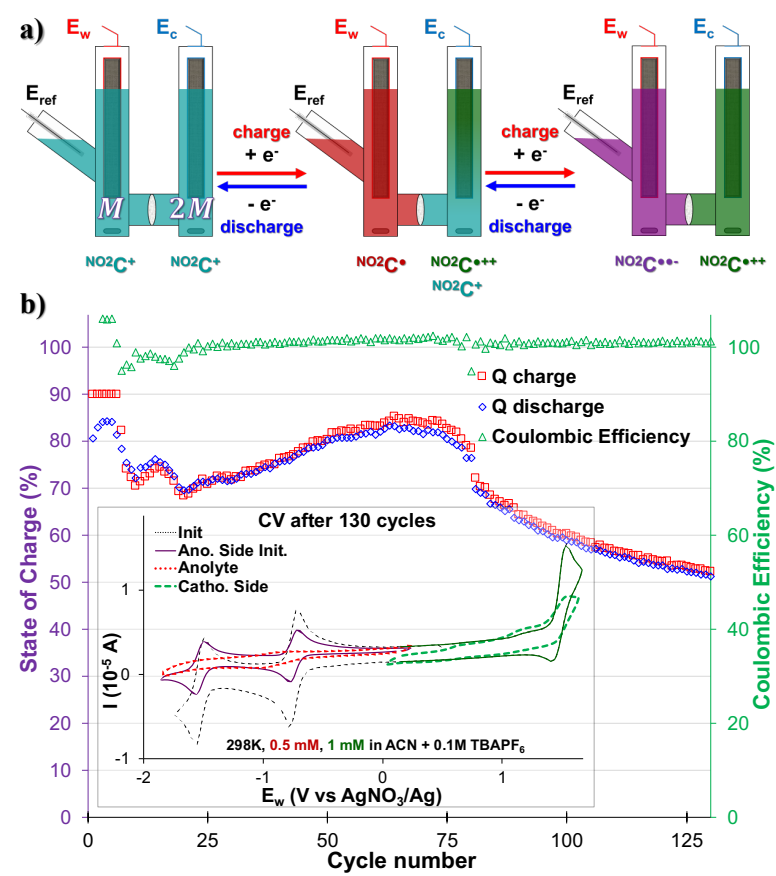

Figure 3. (a) Scheme showing the bi-electronic reduction charge-discharge cycles in a $1: 2{ }^{{ }^{\mathbf{O} 2}} \mathbf{C}^{+}$concentration H-cell. The color code is indicative of the electrolyte oxidation degree. (b) Q of charge-discharge processes and Coulombic efficiency monitoring over 130 cycles of bi-electronic exchange. Inset shows $\mathrm{CV}$ analysis at $100 \mathrm{mV} / \mathrm{s}$ of the respective contents of each side of the cell after 130 cycles.

A CCCV GCPL protocol of $|5| \mathrm{mA}$ with potential boundaries at $-2.07 \mathrm{~V}$ and $-0.49 \mathrm{~V} v s \mathrm{E}_{\text {ref }}$ limited at $90 \%$ SOC was then applied and monitored along 125 cycles (Figure 3b). It was noted that, despite an excellent CE close to $100 \%$, the capacity of our system fluctuated a lot over the course of the experiment. Thus, as early as the 6th cycle, it was noted that the capacity of our system decreased from $90 \%$ to $70 \%$ in cycle 10 . We observe a "rebound" between cycle 10 and 20, leading the capacity of our system $<70 \%$ $\mathrm{Q}_{\text {theoretical. }}$ The capacity of our system slightly increases then to reach a value of $84 \%$ in cycle 74 , and then quickly drops. It then loses $0.75 \%$ per capacity cycle, reaching a value of $53 \%$ in the 125 th cycle. This type of behavior observed also by Binnemans' group for a double reduction of their ROM, has not yet been elucidated. ${ }^{36}$ Unfortunately, no clearly defined plateaux in the $\mathrm{E}_{\mathrm{w}}$ voltage curves was observed during the charge-discharge cycles (see Figure S17). The intensity of the current used and the low ROM concentration of the monitored compartment are probably to blame $(0.5 \mathrm{mM}$ at $|5| \mathrm{mA})$.

$\mathrm{b}$ inset and Figure S17) provided further informations. As was noted for the monopolarization experiment, the catholytic compartment containing the ${ }^{\mathrm{NO} 2} \mathrm{C}^{+}$into ${ }^{\mathrm{NO} 2} \mathrm{C}^{\bullet++}$ process is degraded and exhibited a broadened 
profile (Figure 3b inset green trace). The anodic compartment, which was stable during monopolarization experiment, shows a serious deterioration of the electro-active material after 130 cycles (Figure 3b inset red trace). The electronic processes $E_{1 / 2}{ }^{\operatorname{Red} 1}$ and $\mathrm{E}_{1 / 2}{ }^{\mathrm{Red} 2}$ are almost indistinguishable, and the electrochemical profile is severely altered, more than the cathodic compartment. In view of these results, one can legitimately think that the low stability of the ${ }^{{ }^{\mathbf{O}} \mathbf{2}} \mathbf{C}^{\bullet \bullet-}$, previously noted and supported by our DFT calculations (see Figures S911 ), is one of the weak points of the system. Furthermore, the appearance of a "bounce" in the capacity between cycle 10 and 20 could be linked to diffusion effects. Indeed, our H-cell model is a socalled "static" model, and in the configuration where ${ }^{\mathrm{NO}} \mathrm{C}^{+}$is present in a 1:2 ratio, diffusion effects at the interface - which is here a porous frit and not a selective membrane - may have a major role. Nevertheless, while the robustness of the system requires to be improved, the simple addition of $\mathrm{NO}_{2}$ group onto the DMQA core allowed access to a second process in reduction, and a very high voltage battery of $3.02 \mathrm{~V}$.

\section{BIPOLARIZATION CYCLING, "STRESS-TEST"}

The symmetrical properties of ${ }^{{ }^{02}} \mathbf{C}^{+}$, where the system can be charged independently by transferring electrons into one or the other side of the cell, allow us to carry out bi-electronic cycling tests by polarizing the battery in the opposite direction. Given the poor results obtained during the training of $\mathrm{E}_{1 / 2}{ }^{\mathrm{Red} 2}$, we did not consider it necessary to carry out this experiment with ${ }^{\text {NO2 }} \mathrm{C}^{\bullet \bullet-}$ as a negative bound. This protocol consists of a highly stressful two-electron charge and discharge process on each side of the cell at $100 \%$ SOC. This means that the species ${ }^{{ }^{\mathbf{O}} 2} \mathbf{C}^{\bullet++}$ and ${ }^{{ }^{N O 2}} \mathrm{C}^{\bullet}$ will be formed successively in each compartment over time (Figure 4a). These two-electron cycling processes, labeled "Stress Test" are likely to shorten the life of the battery and are not meant to describe the energy storage ability of our electrolyte under these conditions. ${ }^{43}$ The experiment will however provide information about the sturdiness of this electrolyte.

A CCCV GCPL sequence with a $|5| \mathrm{mA}$ current, setting potential boundaries at $1.55 \mathrm{~V}$ and $-1.49 \mathrm{~V}$ vs $E_{\text {ref, }}$ was therefore started from the initial state of this symmetrical battery (Figure 4a). In the first step, the working electrode side of the cell was "charged" of electrons with a cutoff potential of $-1.49 \mathrm{~V}$ to full reduction of ${ }^{\mathrm{NO} 2} \mathrm{C}^{+}$in ${ }^{\mathrm{NO} 2} \mathrm{C}^{\bullet}$ (Figure 4a, purple arrow). Then a positive $5 \mathrm{~mA}$ current was applied at $1.55 \mathrm{~V}$ (Figure 4a, red arrow) and two electrons were sequentially exchanged, taking ${ }^{\mathrm{NO} 2} \mathrm{C}^{\bullet}$ to ${ }^{{ }^{\mathrm{O}} 2} \mathrm{C}^{\bullet++}$.

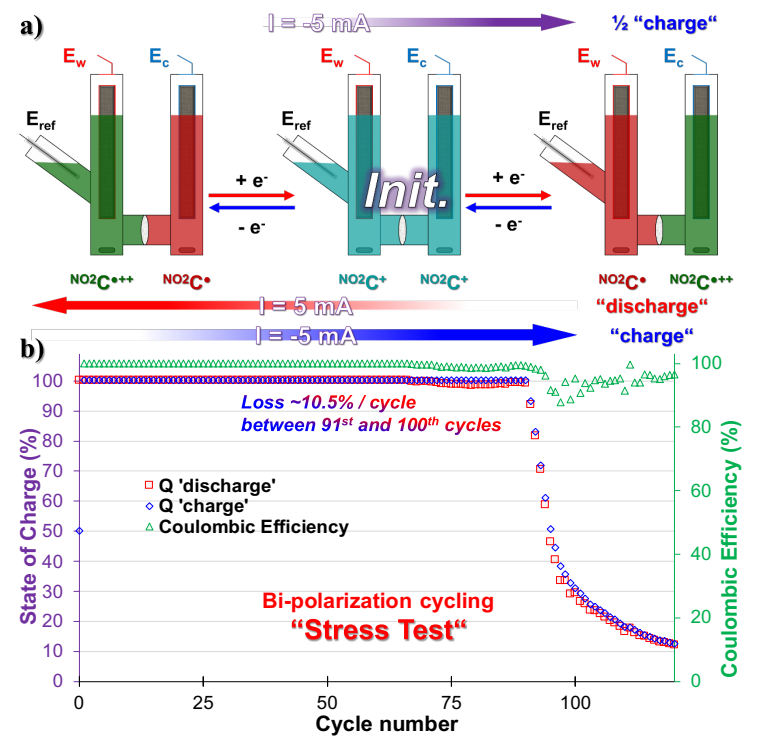

Figure 4: (a) Scheme showing the bi-electronic charge-discharge cycles in a symmetric $\mathrm{H}$-cell as stress test. The color code is indicative of the electrolyte oxidation degree. (b) Q of charge-discharge processes and Coulombic efficiency monitoring over 120 cycles of bi-electronic exchange.

Finally, the current was reversed to $-1.49 \mathrm{~V}$ to "charge" the electrons in the working electrode side of the cell back to ${ }^{\mathrm{NO} 2} \mathrm{C}^{\bullet}$ (Figure 4a blue arrow). The continuous alternation of steps red and blue corresponds to a cycle. Unfortunately, over the course of the experiment, monitoring the value of $E_{w}$ voltage curves is not representative of the conversion processes of ${ }^{{ }^{\mathbf{O} 2}} \mathrm{C}^{\bullet}$ to ${ }^{\mathrm{NO} 2} \mathrm{C}^{+}$and ${ }^{\mathrm{NO} 2} \mathrm{C}^{+}$to ${ }^{\mathrm{NO} 2} \mathrm{C}^{\bullet++}$ (see Figure S20-21).

As shown by the green triangles, the $\mathrm{CE}$ was constant and close to $100 \%$ until the $90^{\text {th }}$ cycle, with a quasiconstant full capacity $\mathrm{Q}=100 \% \mathrm{SOC}$ for two-electron cycling. Then a drastic drop in $\mathrm{Q}$ with an irrecoverable capacity loss of $70 \%$ capacity between cycles 91 and 100 was observed, and the system then degrades more slowly to reach a value of $12.5 \%$ SOC in the $120^{\text {th }}$ cycle (Figure $\mathbf{4 b}$ ). This associated to a slight decrease in CE started at the $91^{\text {rst }}$ cycle which varies between $90 \%$ and $98 \%$ until the end of the experiment. This electrolyte fatigue has been correlated to the degradation of the species during the oxidation phenomenon in ${ }^{\mathbf{N O 2}} \mathbf{C}^{\bullet++}$ and is probably the source of weakness of our battery.

However, during the stress test the ${ }^{\mathrm{NO}^{2}} \mathrm{C}^{+}$demonstrated a higher robustness than its parent ${ }^{\mathrm{H}} \mathbf{C}^{+}$. Indeed, 90 cycles could be reached without degradation of the capacity, i.e. $+12.5 \%$ compared to ${ }^{\mathrm{H}} \mathbf{C}^{+} .{ }^{40} \mathrm{We}$ can directly correlate this robustness improvement to the increase in solubility of $\mathbf{C}^{+}$and more specifically to that of the radical dication ${ }^{\mathrm{NO} 2} \mathrm{C}^{\bullet++}$ compared to ${ }^{\mathrm{H}} \mathrm{C}^{\bullet++}$ which allows a longer cyclability over time with less solubility issues in extremely stressful conditions. 


\section{Conclusions}

The need to evolve RFBs tends towards the use of organic Bipolar Redox-Active Molecules. ${ }^{58}$ This is an elegant solution to the challenge of cross contamination and membrane costs. In the case of NARFB, the choice of solvent will allow a very large potential window and increase the accessible energy density. The question of ROM solubility remains a critical point. During this study, we set out to improve these different parameters. Thus, by a quasiquantitative late nitration of our previous ROM, we were able to:

- boost the solubility of our $\mathbf{C}^{+}$electrolyte by 4.8 times allowing a longer lifetime during the stress test.

- expand the open circuit voltage (OCV) between $\mathrm{E}_{1 / 2}{ }^{\mathrm{Ox}}$ and $\mathrm{E}_{1 / 2}{ }^{\mathrm{Red} 1}$ by $120 \mathrm{mV}$ (monopolarization).

- increase the number of reversible electronic events to 3 , with a second event, allowing an $\mathrm{OCV} \mathrm{E}_{1 / 2}{ }^{\mathrm{Ox}}$ $\mathrm{E}_{1 / 2}{ }^{\operatorname{Red} 2}$ of $3.02 \mathrm{~V}$ (double reduction cycling).

Thus, despite the moderate stability of ${ }^{\mathrm{NO}} \mathbf{C}^{++\bullet}$ and the ${ }^{\mathrm{NO}} \mathrm{C}^{-\bullet \bullet}$, this simple modification of the $\mathrm{DMQA}^{+}$core allowed us to multiply the initial energy density by 5 times in the case of monoelectronic cycling. Moreover, the double anode reduction cycling demonstrated an $E_{d}$ value of $12.5 \mathrm{Wh} / \mathrm{L}$ that is closer to the one offered by current aqueous VRFBs $(15-25 \mathrm{Wh} / \mathrm{L}) .^{59}$

The simplicity of the structural modification and the results obtained underline the values that DMQAs core present as ROMs library for symmetrical ORFBs.

\section{Author Contributions}

T.L.G. and J.M. wrote the manuscript, planned the experiments, and discussed their conclusions. J.M. conducted all experiments; D.M. performed the DFT calculations; M.M.H. synthetized ${ }^{\mathrm{NO}} \mathbf{C}^{+}$.

\section{Conflicts of interest}

There are no conflicts to declare.

\section{Acknowledgements}

We are grateful to the University of Arizona and Salt River Project for financially supporting this work. J.M. is grateful to Dr. Vincent Caldeira from Grenoble INPLEPMI/EasylSA for helpful discussions.

\section{References}

1 M. S. Dresselhaus and I. L. Thomas, Nature, 2001, 414, 332-337.
Z. Yang, J. Zhang, M. C. W. Kintner-Meyer, X. Lu, D. Choi, J. P. Lemmon and J. Liu, Chem. Rev., 2011, 111, 3577-3613.

S. P. S. Badwal, S. S. Giddey, C. Munnings, A. I. Bhatt and A. F. Hollenkamp, Front. Chem., 2014, 2, $1-28$.

T. M. Gür, Energy Environ. Sci., 2018, 11, 26962767.

J. B. Goodenough, M. S. Whittingham and A. Yoshino, R. Swedish Acad. Sci., 2019 , https://www.nobelprize.org/prizes/chemistry/20 19/p.

A. Masias, J. Marcicki and W. A. Paxton, ACS Energy Lett., 2021, 621-630.

J.-M. Tarascon and M. Armand, Nature, 2001, 414, 359-367.

M. Winter, B. Barnett and K. Xu, Chem. Rev., 2018, 118, 11433-11456.

J. Rugolo and M. J. Aziz, Energy Environ. Sci., 2012, 5, 7151-7160.

G. L. Soloveichik, Chem. Rev., 2015, 115, 1153311558.

M. Park, J. Ryu, W. Wang and J. Cho, Nat. Rev. Mater., 2017, 2, 16080.

L. F. Arenas, C. Ponce de León and F. C. Walsh, Curr. Opin. Electrochem., 2019, 16, 117-126.

D. G. Kwabi, Y. Ji and M. J. Aziz, Chem. Rev., 2020, 120, 6467-6489.

P. Alotto, M. Guarnieri and F. Moro, Renew. Sustain. Energy Rev., 2014, 29, 325-335.

W. Lu, X. Li and H. Zhang, Phys. Chem. Chem. Phys., 2017, 20, 23-35.

H. R. Jiang, W. Shyy, M. C. Wu, R. H. Zhang and T. S. Zhao, Appl. Energy, 2019, 233-234, 105-113.

H. R. Jiang, J. Sun, L. Wei, M. C. Wu, W. Shyy and T. S. Zhao, Energy Storage Mater., 2020, 24, 529540.

R. A. Potash, J. R. McKone, S. Conte and H. D. Abruña, J. Electrochem. Soc., 2016, 163, A338A344.

W. Wang, S. Kim, B. Chen, Z. Nie, J. Zhang, G.-G. Xia, L. Li and Z. Yang, Energy Environ. Sci., 2011, 4, 4068-4073.

P. J. Cabrera, X. Yang, J. A. Suttil, K. L. Hawthorne, R. E. M. Brooner, M. S. Sanford and L. T. Thompson, J. Phys. Chem. C, 2015, 119, 1588215889.

Y. A. Gandomi, D. S. Aaron, J. R. Houser, M. C. Daugherty, J. T. Clement, A. M. Pezeshki, T. Y. Ertugrul, D. P. Moseley and M. M. Mench, J. Electrochem. Soc., 2018, 165, A970-A1010.

M. Park, E. S. Beh, E. M. Fell, Y. Jing, E. F. Kerr, D. Porcellinis, M. Goulet, J. Ryu, A. A. Wong, R. G. Gordon, J. Cho and M. J. Aziz, Adv. Energy Mater., 
2019, 9, 1900694.

DOE Office of ARPR-E. ARPA-E, GRIDS Program Overview, https://arpae.energy.gov/sites/default/files/documents/files/ GRIDS_ProgramOverview.pdf. U.S. DEPARTMENT OF HEALTH AND HUMAN SERVICES Public Health Service Agency for Toxic Substances and Disease Registry, in ATSDR's Toxicological Profiles, CRC Press, 2012.

25 T. B. Schon, B. T. McAllister, P.-F. Li and D. S. Seferos, Chem. Soc. Rev., 2016, 45, 6345-6404.

26 J. Winsberg, T. Hagemann, T. Janoschka, M. D. Hager and U. S. Schubert, Angew. Chemie - Int. Ed., 2017, 56, 686-711.

27 X. Wei, W. Pan, W. Duan, A. Hollas, Z. Yang, B. Li, Z. Nie, J. Liu, D. Reed, W. Wang and V. Sprenkle, ACS Energy Lett., 2017, 2, 2187-2204.

28 T. Janoschka, C. Friebe, M. D. Hager, N. Martin and U. S. Schubert, ChemistryOpen, 2017, 6, 216-220.

29 Y. Ding, C. Zhang, L. Zhang, Y. Zhou and G. Yu, Chem. Soc. Rev., 2018, 47, 69-103.

30 R. F. Service, Science, 2018, 362, 508-509.

31 J. Luo, B. Hu, M. Hu, Y. Zhao and T. L. Liu, ACS Energy Lett., 2019, 4, 2220-2240.

32 R. P. Fornari and P. de Silva, WIREs Comput. Mol. Sci., 2020, 1-16.

33 S. Jin, Y. Jing, D. G. Kwabi, Y. Ji, L. Tong, D. De Porcellinis, M.-A. Goulet, D. A. Pollack, R. G. Gordon and M. J. Aziz, ACS Energy Lett., 2019, 4, 1342-1348.

34 J. Chai, A. Lashgari, Z. Cao, C. K. Williams, X. Wang, J. Dong and J. "Jimmy" Jiang, ACS Appl. Mater. Interfaces, 2020, 12, 15262-15270. H. Chen, Z. Niu, J. Ye, C. Zhang, X. Zhang and Y. Zhao, ACS Appl. Energy Mater., 2021, 4, 855-861. P. Geysens, Y. Li, I. Vankelecom, J. Fransaer and K. Binnemans, ACS Sustain. Chem. Eng., 2020, 8, 3832-3843.

K. Lin, R. Gómez-Bombarelli, E. S. Beh, L. Tong, Q. Chen, A. Valle, A. Aspuru-Guzik, M. J. Aziz and R. G. Gordon, Nat. Energy, 2016, 1, 16102.

P. Leung, T. Martin, M. Liras, A. M. Berenguer, R. Marcilla, A. Shah, L. An, M. A. Anderson and J. Palma, Appl. Energy, 2017, 197, 318-326.

B. Hu, J. Luo, M. Hu, B. Yuan and T. L. Liu, Angew. Chemie Int. Ed., 2019, 58, 16629-16636.

J. Moutet, J. M. Veleta and T. L. Gianetti, ACS Appl. Energy Mater., 2021, 4, 9-14.
I. H. Delgado, S. Pascal, A. Wallabregue, R. Duwald, C. Besnard, L. Guénée, C. Nançoz, E. Vauthey, R. C. Tovar, J. L. Lunkley, G. Muller and J. Lacour, Chem. Sci., 2016, 7, 4685-4693.

Y. Yan, S. G. Robinson, M. S. Sigman and M. S. Sanford, J. Am. Chem. Soc., 2019, 141, 1530115306.

P. W. Antoni, T. Bruckhoff and M. M. Hansmann, J. Am. Chem. Soc., 2019, 141, 9701-9711.

K. Gong, Q. Fang, S. Gu, S. F. Y. Li and Y. Yan, Energy Environ. Sci., 2015, 8, 3515-3530.

A. Korshunov, M. J. Milner, M. Grünebaum, A. Studer, M. Winter and I. Cekic-Laskovic, J. Mater. Chem. A, 2020, 8, 22280-22291.

A. C. Shaikh, J. Moutet, J. M. Veleta, M. M. Hossain, J. Bloch, A. V. Astashkin and T. L. Gianetti, Chem. Sci., 2020, 11, 11060-11067.

X. Xing, Q. Liu, W. Xu, W. Liang, J. Liu, B. Wang and J. P. Lemmon, ACS Appl. Energy Mater., 2019, 2, 2364-2369.

Y. Yan, T. P. Vaid and M. S. Sanford, J. Am. Chem. Soc., 2020, jacs.0c07464.

B. Huskinson, M. P. Marshak, C. Suh, S. Er, M. R. Gerhardt, C. J. Galvin, X. Chen, A. Aspuru-Guzik, R. G. Gordon and M. J. Aziz, Nature, 2014, 505, 195198.

X. Wei, W. Duan, J. Huang, L. Zhang, B. Li, D. Reed, W. Xu, V. Sprenkle and W. Wang, ACS Energy Lett., 2016, 1, 705-711.

K. H. Hendriks, S. G. Robinson, M. N. Braten, C. S. Sevov, B. A. Helms, M. S. Sigman, S. D. Minteer and M. S. Sanford, ACS Cent. Sci., 2018, 4, 189-196.

X. Yu and A. Manthiram, Sustain. Energy Fuels, 2018, 2, 1452-1457.

R. S. Nicholson, Anal. Chem., 1965, 37, 1351-1355. I. Lavagnini, R. Antiochia and F. Magno, Electroanalysis, 2004, 16, 505-506.

55 C. DeBruler, B. Hu, J. Moss, X. Liu, J. Luo, Y. Sun and T. L. Liu, Chem, 2017, 3, 961-978.

56 J. Luo, B. Hu, C. Debruler and T. L. Liu, Angew. Chemie Int. Ed., 2018, 57, 231-235.

L. Tong, Y. Jing, R. G. Gordon and M. J. Aziz, ACS Appl. Energy Mater., 2019, 2, 4016-4021.

$58 \mathrm{M}$. Li, J. Case and S. D. Minteer, ChemElectroChem, 2021, celc. 202001584.

59 A. Clemente and R. Costa-Castelló, Energies, 2020, 13, 4514. 